\title{
Uso de simulação no ensino de urgência e emergência pré-hospitalar para discentes de medicina: Relato de experiência
}

\author{
Use of simulation in pre-hospitalization urgency and emergency education for medical students: \\ Experience report
}

Mario Henrique Chaves Guedes ${ }^{\dagger *}$, Jéssica Teles Sousa Gomes ${ }^{\dagger}$, Andréia Santos Rezende de Almeida ${ }^{\dagger}$, André Luiz Dias Lima Bonfim†, Luiz Felipe Furtado Vilela†, Paula Pitta de Resende Côrtes

\begin{abstract}
Resumo
Como citar esse artigo. Guedes $\mathrm{MHC}$; Gomes JTS; de Almeida ASR; Bonfim ALDB; Vilela LFF; Côrtes PPR. Uso de simulação no ensino de urgência e emergência pré-hospitalar para discentes de medicina: Relato de experiência. Revista de
Saúde. 2017 Jan./Jun.; 08 (1): 08-14.

As situações de emergência requerem intervenção imediata, de forma objetiva e eficaz, de modo a reduzir as possíveis sequelas e aumentar a sobrevida das vítimas. Por esse motivo, a ONG Projeto Vidas, composta por alunos do curso de Medicina da Universidade Severino Sombra, através do ensino por simulações, promove oportunidades para aquisição de habilidades cognitivas e psicomotoras de forma integrada nos seus cursos de primeiros socorros, permitindo aos estudantes a análise de seus desempenhos e autorreflexões. O objetivo deste estudo é relatar a experiência de um curso realizado por integrantes da ONG Projeto Vidas, com duração de 8 dias, com aulas expositivas e dinâmicas com simulações de atendimento, abordando diversos temas de cuidado pré-hospitalar. Ao início do curso, foi aplicado um pré-teste para a verificação do conhecimento prévio em situações de urgência e emergência. Ao final, foi realizado um grande simulado com múltiplas vítimas, onde os alunos tiveram a oportunidade de testar seus conhecimentos e sua capacidade técnica. Foi feito um pós-teste para avaliar o crescimento pedagógico e prático dos alunos, onde foi verificada uma melhora de $64 \%$ no desempenho geral. Sendo assim, concluímos que esta significativa melhora das equipes ao final do simulado e ao final do pós-teste, demonstraram a relevância do ensino através de simulações para sedimentação do conhecimento, reforçando que o estudante de medicina deve ser inserido precocemente em simulações para garantir a conexão entre os conhecimentos teórico-práticos e sua aplicação em situações reais.

Palavras-chave: Medicina de Emergência; Educação Médica; Simulação de Paciente; Avaliação.
\end{abstract}

\begin{abstract}
Emergency situations require immediate intervention, objectively and effectively to reduce possible sequels and increase victims' survival chances. The Non-governamental Organization (NGO) "Projeto Vidas", composed by Medicine students at Severino Sombra University uses simulations to promote opportunities for acquisition of cognitive and psychomotor skills in an integrated manner, allowing students to analyze and self-relect on their performances during a first-aid course. This study reports on the experience of a course held by members of the NGO "Projeto Vidas" lasting 8 days, with lectures and dynamic simulations, addressing various pre-hospitalization themes. At the beginning of the course, a pretest was applied to verify prior knowledge in urgency and emergency situations. The course ended with a large simulation with multiple victims, where students had the opportunity to test the acquired knowledge and their technical skills. A post-test to evaluate the pedagogical and practical growth of participants showed a $64 \%$ improvement in the students performance. This significant improvement demonstrated the relevance of teaching through simulations to sediment knowledge. This approach reinforces the need for medical students to be inserted in case-scenarios through simulations in order to ensure the connection between the theoretical-practical knowledge and its application in real situations. Keywords: Emergency Medicine; Medical Education; Patient Simulation; Evaluation.
\end{abstract}

\section{Introdução}

As diretrizes curriculares nacionais para os cursos de graduação em Medicina preconizam a graduação de médicos aptos a atuarem nos diferentes níveis de atenção à saúde, incluindo Rede de Urgência e Emergênciaª As situações de emergência requerem intervenção imediata, de forma objetiva e eficaz, de modo a reduzir as possíveis sequelas e aumentar a sobrevida das vítimas $^{2}$. Anualmente, cerca de 60 milhões de pessoas sofrem algum tipo de traumatismo. Isto corresponde a uma em cada seis internações hospitalares, ocupando a terceira posição entre as causas de morte por trauma no Brasil ${ }^{3}$.

Afiliação dos autores: † Universidade Severino Sombra, Pró-reitoria de Ciências Médicas, Discentes do Curso de Medicina, Vassouras - RJ, Brasil.

\$ Universidade Severino Sombra, Pró-reitoria de Ciências Médicas, Docente do Curso de Medicina, Vassouras - RJ, Brasil. 
É provável que um médico, que teve na sua formação o treinamento em técnicas de suporte básico de vida, consiga obter mais naturalidade no tratamento ao politraumatizado e, por conseguinte, maior eficácia numa situação em que o bom uso do tempo é primordial ${ }^{2}$. Portanto, é inegável a importância da aquisição das habilidades que sustentem o conhecimento científico, garantindo maior eficácia nessas situações ${ }^{4}$.

A simulação é uma poderosa ferramenta de treinamento de competências porque permite ao aluno atuar em ambiente protegido, seguro e controlado, sem complicadores presentes em situações reais ${ }^{5}$, de modo a repetir o desempenho de uma tarefa inúmeras vezes, seguido de feedback imediato, adequado e sistematizado. Trata-se de metodologia racional com alcance desde o treinamento de habilidades básicas simples (capacidades cognitivas, afetivas e psicomotoras mobilizadas em determinado contexto para a realização de tarefas) $)^{6}$, até complexos aspectos comportamentais (atividade global ou conjunto de atos de um indivíduo perante uma situação) ${ }^{7}$.

A introdução de simulações para melhorar o ensino na formação médica é de extremo impacto para os alunos, pois promove oportunidades para aquisição de habilidades cognitivas e psicomotoras de forma integrada. Além disso, essas situações simuladas são importantes ferramentas pedagógicas para 0 desenvolvimento do ensino de procedimentos clínicos, permitindo, inclusive, aos estudantes a análise de seus desempenhos e a realização de autorreflexão ${ }^{8,9}$, sendo bem estabelecido que as atividades de ensino que priorizem a prática seguida de feedback adequado, têm enorme potencial de efetivamente corrigirem rumos e comportamentos, com elevada validade preditiva ${ }^{10}$.

Portanto, é consenso de que o treinamento precoce favorece a retenção de conhecimentos e reforça o conceito da obrigação social de ajudar o próximo ${ }^{11}$.

A ONG Projeto Vidas, organizadora de cursos de primeiros socorros, é formada por acadêmicos de diversos períodos do curso de Medicina da Universidade Severino Sombra (USS), localizada na cidade de Vassouras - RJ, e tem como objetivo a utilização de situações simuladas de riscos, acidentes e resgates, visando qualificar a formação dos estudantes ingressantes através do desenvolvimento de habilidades cognitivas e psicomotoras imprescindíveis ao exercício da medicina.

Oobjetivodopresenteartigoérelataraexperiência vivenciada por estudantes do curso de Medicina da USS através do curso de primeiros socorros da ONG Projeto Vidas e a aquisição de habilidades durante situações simuladas no atendimento pré-hospitalar de urgência e emergência.

\section{Relato de experiência}

Há 16 anos, a ONG Projeto Vidas promove atividades de ensino direcionadas para acadêmicos da área de saúde e à população em geral e, semestralmente, em parceria com a USS, é ministrado o Curso de Primeiros Socorros, com ampla abordagem em atendimento pré-hospitalar baseado no PHTLS (Pre Hospital Trauma Life Support) e BLS (Basic Life Support)

A atividade proposta tem início com um curso teórico e prático de atendimento pré-hospitalar com carga horária de 36 horas e duração de 8 dias, sendo o primeiro dia essencialmente teórico e o último dia essencialmente prático, onde é realizado um grande simulado com múltiplas vítimas.

As aulas do curso são ministradas pelos integrantes mais experientes da $\mathrm{ONG}$, denominados de monitores, os quais fizeram capacitações teóricopráticas com profissionais médicos das áreas trabalhadas, sendo abordados os seguintes temas: Abordagem Inicial ao Politraumatizado; Biomecânica do Trauma; Ferimentos, Hemorragia e Choque; Manutenção das Vias Aéreas; Trauma Torácico; Trauma Abdominal; Trauma Neurológico; Trauma Musculoesquelético; Trauma Pediátrico; Lesões Ambientais; Acidente com Animais Peçonhentos; Ressuscitação Cardiopulmonar; Afogamento; Emergências Clínicas; Atendimento a Múltiplas Vítimas (protocolo START) e Combate ao Incêndio.

O curso se inicia com a aplicação de um pré-teste contendo 23 questões de múltipla escolha (ANEXO 1), que aborda tópicos relevantes do conhecimento em primeiros socorros, a fim de avaliar o nível de conhecimento prévio dos alunos e, ao término de todas as aulas, aplica-se o pós-teste. Este corresponde ao mesmo teste aplicado inicialmente e o objetivo é avaliar o conhecimento adquirido ao longo do curso através da comparação do desempenho dos alunos.

A partir do primeiro dia de curso, antes de se iniciarem as aulas práticas, os alunos são divididos em equipes de 4 pessoas, onde uma pessoa dessa equipe será a responsável pelo primeiro contato com a vítima e por conduzir o atendimento ao designar ações ao restante da equipe, sendo nomeada "número 1". O restante da equipe, além de auxiliar no atendimento à vítima através das ordens do líder do grupo, é responsável pelo equipamento de resgate e por manter a cena do trauma em condições favoráveis ao atendimento. Após a exposição prévia do conteúdo através das aulas teóricas, e de uma aula prática objetiva de cada tema onde as técnicas de atendimento e os materiais de resgate são apresentados (Figura 1), os alunos participam de diversos casos clínicos que exigem da equipe uma boa liderança, entrosamento, 


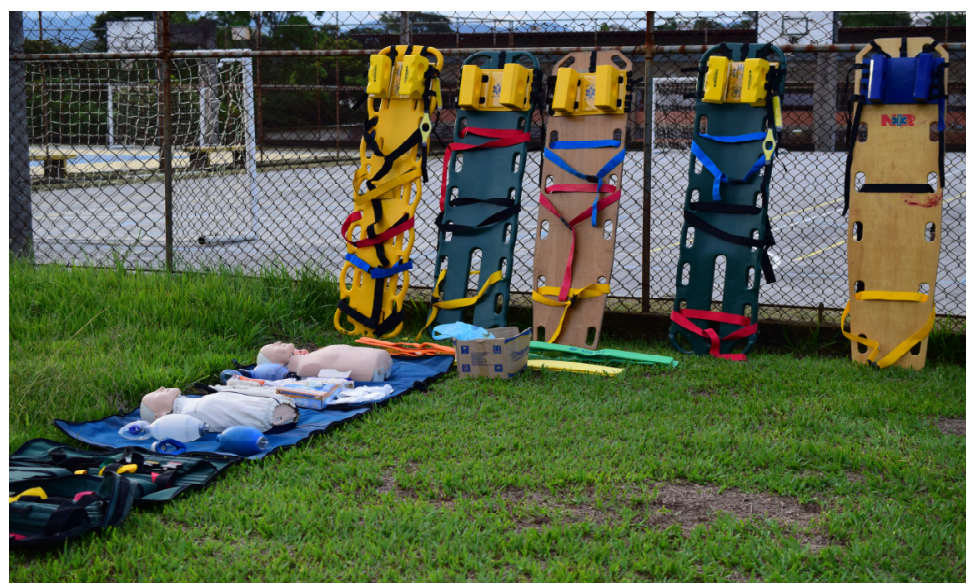

Figura 1. Material para a realização das práticas e do simulado.

raciocínio rápido e manobras eficazes de todos os seus integrantes para a tomada e realização de decisões fundamentais para a sobrevivência da vítima em questão.

Após 7 dias de aulas expositivas e de treinamentos práticos, os integrantes da ONG realizam um grande simulado de atendimento a múltiplas vítimas (Figura 2), com a presença de vítimas com lesões de distintas complexidades até o óbito (Figura 3) para padronizar e normatizar reações e comportamentos das equipes de atendimento, dando a oportunidade aos alunos do curso de colocarem em prática todo o conteúdo que aprenderam durante uma situação de estresse (Figura 4). Ao final da simulação os organizadores avaliam os erros e acertos das equipes, proporcionando aos participantes os comentários necessários para auto avaliação e desenvolvimento de senso crítico.

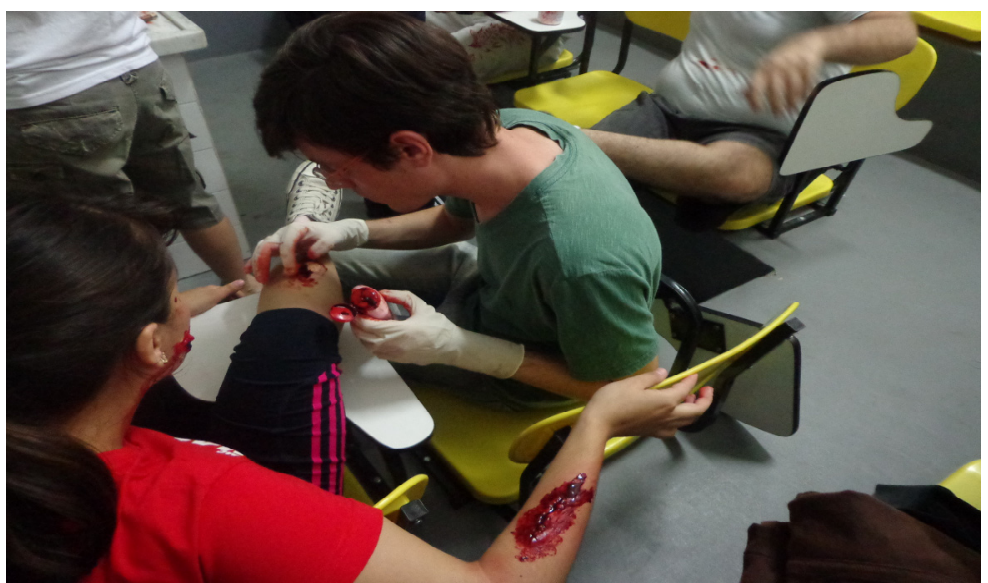

Figura 2. Integrantes da ONG Projeto Vidas e Acadêmicos de Medicina da Universidade Severino Sombra se preparando para o simulado.

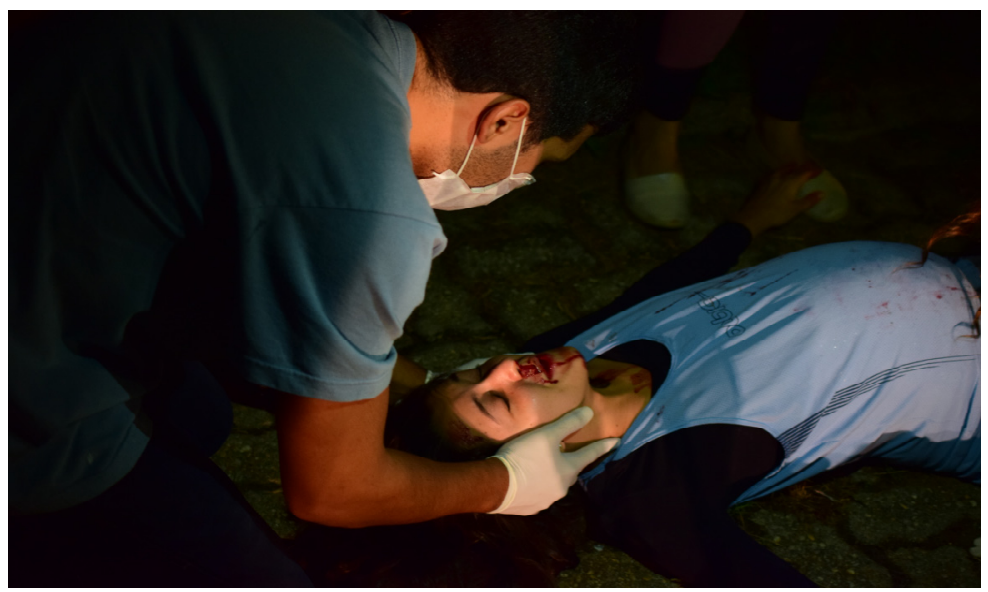

Figura 3. Participante do curso realizando atendimento no simulado. 


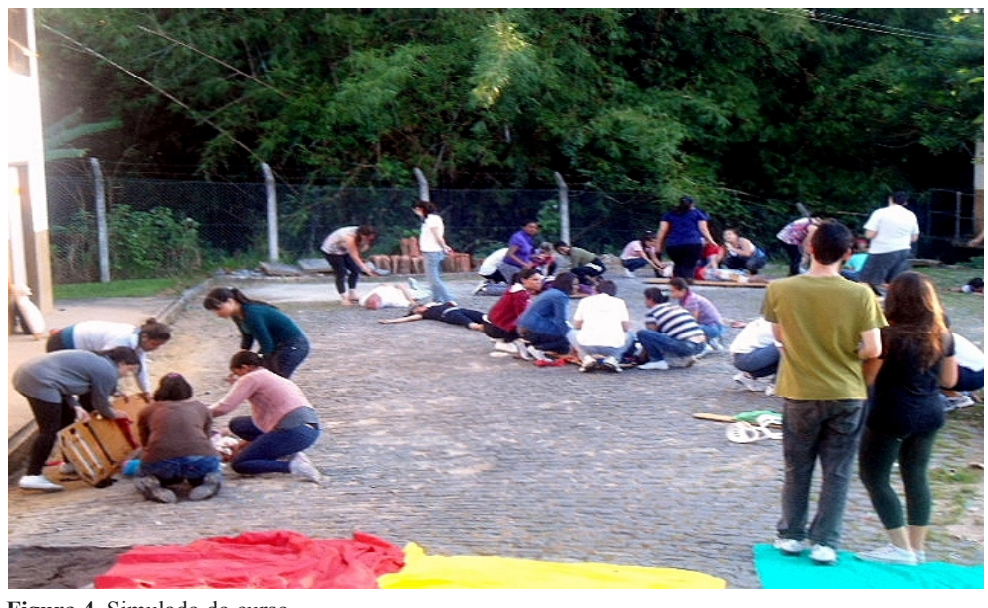

Figura 4. Simulado do curso.

\section{Resultado}

O curso de primeiros socorros contou com a participação de 76 alunos, sendo que 52 participantes eram do sexo feminino e 24 eram do sexo masculino. Foram descartados da média os participantes que deixaram de realizar o pré-teste e/ou o pós-teste, restando ao final, 68 alunos.

Dentre os 68 participantes: 55 (80,9\%) foram do curso Medicina da USS; 4 (5,9\%) foram do curso de Enfermagem da USS; $3(4,4)$ do curso de Biomedicina da USS; $1(1,5)$ do curso de Fisioterapia da USS; 4 $(4,4)$ da Faculdade de Medicina de Valença e $1(1,5)$ cidadão leigo de Vassouras.

Dos 55 participantes do curso de Medicina da USS: 12 estavam cursando o $1^{\circ}$ período; 13 o $2^{\circ}$ período; 14 o $4^{\circ}$ período; 2 o $5^{\circ}$ período; 3 o $6^{\circ}$ período; 8 o $8^{\circ}$ período; 1 o $9^{\circ}$ período; 1 o $10^{\circ}$ período e 1 o $12^{\circ}$ período. Dos 4 participantes do curso de Enfermagem da USS: 1 estava cursando o $9^{\circ}$ período e 3 o $10^{\circ}$ período. Os 3 participantes do curso de Biomedicina da USS estavam cursando o $6^{\circ}$ período. A única participante do curso de Fisioterapia da USS estava cursando o $10^{\circ}$ período. Dos 4 participantes da Faculdade de Medicina de Valença: 1 estava cursando o $2^{\circ}$ período e 3 o $4^{\circ}$ período.

Durante a verificação dos resultados do préteste, foi constatada uma média de acerto de 9,8 questões das 23 possíveis, atingindo uma porcentagem de acerto de $42,4 \%$. Já no pós-teste uma melhora no desempenho dos alunos na ordem de $63,9 \%$, como pode ser observado na Tabela 1 .

\section{Conclusões}

As situações simuladas são importantes ferramentas para desenvolvimento do ensino de procedimentos clínicos o que permite aos estudantes avaliarem seus desempenhos e realizarem autorreflexões.

Os resultados da significativa melhora no desempenho das equipes ao final do simulado e ao final do pós-teste demonstraram a relevância do ensino através de simulações para sedimentação de seu conhecimento. Assim sendo, o estudante de medicina deve ser inserido precocemente em simulações para garantir a conexão dos conhecimentos teórico-práticos e sua aplicação em situações reais.

\section{Referências}

1. Brasil. Ministério da Educação. Conselho Nacional de Educação. Câmara de Educação Superior. Resolução CNE/CES n³ de 20 de junho de 2014. Institui diretrizes curriculares nacionais do curso de graduação em Medicina e dá outras providências. Diário Oficial da União, 23 de junho de 2014; Seção 1:8-11.

2. Maia ER, Gonçalves Júnior J, Lima EP, Campos W, Jovino EM, Fernandes $\mathrm{FF}$, et al. Conhecimentos em atenção préhospitalar e suporte básico de vida por estudantes recémingressos de medicina. Rev Bras Educ Méd. 2014;38(1):59-64.

3. Simões RL, Duarte Neto C, Maciel GSB, Furtado TP, Paulo DNS. Atendimento pré-hospitalar à múltiplas vítimas com trauma simulado. Rev Col Bras Cir. 2012;39(3):230-7.

4. Vieira JE, Tamousauskas MRG. Avaliação das resistências de docentes a propostas de renovações em currículos de graduação em medicina. Revista Brasileira de Educação Médica. 2013;37(1):32-8.

Tabela 1. Médias e porcentagens de acertos nos pré e pós-testes.

\begin{tabular}{ccc}
\hline & Média de acertos & Porcentagem \\
\hline Pré-teste & 9,76 & $42,4 \%$ \\
Pós-teste & 15,3 & $66,3 \%$ \\
Comparação & $+5,50$ & $63,9 \%$ \\
\hline
\end{tabular}


5. Beaubien J, Baker D. The use of simulation for training teamwork skills in health care: how low can you go? Quality and safety in health care. 2004;13(suppl 1):i51-i6.

6. Mesquita R, Duarte F, VIEIRA CPL. Dicionário de psicologia. Plátano Editora. 1996.

7. Wayne DB, Butter J, Siddall VJ, Fudala MJ, Wade LD, Feinglass J, et al. Mastery learning of advanced cardiac life support skills by internal medicine residents using simulation technology and deliberate practice. Journal of general internal medicine. 2006;21(3):251-6.

8. Unroe MA, Shofer SL, Wahidi MM. Training for endobronchial ultrasound: methods for proper training in new bronchoscopic techniques. Current opinion in pulmonary medicine. 2010;16(4):295-300.

9. Shumway JM, Harden RM. AMEE Guide No. 25: The assessment of learning outcomes for the competent and reflective physician. Medical teacher. $2003 ; 25(6): 569-84$.

10. Roppolo LP, Pepe PE. Retention, retention, retention: targeting the young in CPR skills training! Critical Care. 2009;13(5):185.

\section{Anexo I - Questionário}

\section{Organização Não - Governamental PROJETO VIDAS}

Vassouras - RJ

Estudo, Treinamento e Atendimento Pré-Hospitalar

Nome:

Curso/Período:

1) Você foi chamado para atender às seguintes vítimas de um desabamento:

Mariana: Deambula, $\mathrm{EC}=1,5 \mathrm{~s}$ e obedece à ordem simples.

Danilo: Não deambula, respira após reposicionamento de VA.

João Paulo: Não deambula, FR= 23 irpm, $\mathrm{EC}=2,7 \mathrm{~s}$ Raquel: Não deambula, $F R=27$ irpm, obedece à ordem simples.

Zacaron: Não deambula, FR=29 irpm, EC=1,6s, não obedece à ordem simples.

Qual é a ordem de prioridade de atendimento?

a) Danilo, João Paulo, Zacaron, Raquel, Mariana.

b) Raquel, João Paulo, Zacaron, Mariana, Danilo.

c) Zacaron, João Paulo, Raquel, Danilo, Mariana.

d) Mariana, Raquel, João Paulo, Zacaron, Danilo.

e) Zacaron, Raquel, Danilo, João Paulo, Mariana.

2) Ao abordar uma vítima inconsciente, qual deve ser a primeira preocupação do socor-rista?

a) Avaliar a FC e o EC.

b) Procurar os possíveis ferimentos do corpo.

c) Manter a via aérea pérvia. d) Observar se as pupilas estão foto reagentes.

e) Administrar oxigênio.

3) Você estava viajando sozinho de carro em um dia chuvoso quando o carro que estava na sua frente derrapou na pista e capotou. Qual seria a conduta correta diante dessa situ-ação?

a) Não parar e avisar no posto mais próximo a existência do acidente.

b) Ir abordar sozinho as vítimas.

c) Retirar as vítimas do carro.

d) Fazer a sinalização na pista e chamar o socorro.

e) Ligar para algum parente das vítimas.

\section{4) Abrasão é:}

a) Separação de 2 superfícies articulares.

b) Lesão causada pelo atrito com superfícies ásperas.

c) Ruptura total ou parcial das fibras de um ligamento.

d) Lesão pelo impacto de um objeto rombo ao corpo.

e) Lesão causada por objetos com bordas irregulares.

5) Qual é a causa mais comum de obstrução das vias aéreas em pacientes inconscientes?

a) Corpos estranhos (chicletes, próteses).

b) Fraturas de face.

c) Broncoespasmo.

d) Queda da base da língua.

e) Vômito.

6) Qual é o sinal / sintoma tardio de reconhecimento do estado de choque em uma víti-ma?

a) Vasoconstricção periférica.

b) Taquicardia.

c) Taquipneia.

d) Sudorese.

e) Hipotensão arterial.

7) Esquematize em ordem de sensibilidade à isquemia (do mais sensível para o menos sensível), os seguintes órgãos:

a) Pele, Músculos, Fígado, Rins, Pulmões, Coração.

b) Fígado, coração, Pulmões, Rins, Pele, Músculos.

c) Coração, Pulmões, Rins, Fígado, músculos, Pele.

d) Rins, Fígado, Coração, Pulmões, Pele, Músculos.

e) Pele, Músculos, Coração, Pulmões, Rins, Fígado.

8) Qual é a outra lesão que geralmente acompanha hemotórax maciço?

a) Tamponamento pericárdico

b) Pneumotórax 

c) Ruptura de aorta
d) Ruptura de baço
e) Ruptura brônquica

9) Ao analisarmos um veículo que se chocou contra um poste, observamos que o para-brisa está "estrelado". Sabendo que a vítima não fazia o uso do cinto de segurança de 3 pontos e que o carro não possuía air-bags, devemos suspeitar que ocorreu mais provavelmente os seguintes padrões de lesão, além da lesão da cabeça:

a) Lesão do tórax, joelhos e tornozelos.

b) Lesão de ombro e de pelve.

c) Lesão de tórax, coluna cervical e abdome.

d) Lesão do membro inferior e abdome.

e) Lesão de extremidades e coluna cervical.

10) Em um acidente automobilístico a equipe de resgate encontrou entre as vítimas uma gestante no $8^{\circ}$ mês de gravidez, queixando-se de contrações a cada 90s, com FR: 23 irpm, FC: 74 bpm, PA: $120 \times 90$ mmHg. Qual a conduta a ser adotada nesse caso?

a) Imobilizar a coluna cervical e transportar em decúbito lateral esquerdo.

b) Imobilizar a coluna cervical e fazer com que ela fique em pé, até o transporte chegar.

c) Preparar o local para parto de emergência.

d) Aguardar as contrações chegarem a intervalos de $15 \mathrm{~s}$.

e) Colocar a gestante em posição ginecológica.

11) Qual a proporção de compressões torácicas / insuflações respiratórias no $\mathrm{RCP}$ em adultos?

a) 30 compressões para 2 insuflações.

b) 3 compressões para 1 insuflação.

c) 15 compressões para 1 insuflação.

d) 200 compressões em $2 \mathrm{~min}$, seguido de 2 insuflações.

e) 100 compressões em $1 \mathrm{~min}$, seguido de 2 insuflações.

12) A ordem correta de prioridade no atendimento a vítimas triadas é:

a) Vermelho - amarelo - preto - verde.

b) Amarelo - verde - vermelho - preto.

c) Preto - verde - amarelo - vermelho.

d) Verde - amarelo - vermelho - preto.

e) Vermelho - amarelo - verde - preto.

13) De acordo com a ECG (Escala de Coma de Glasgow) organize as vítimas abaixo, da mais grave para a menos grave:

Vítima $01=>$
Resp. Ocular $=>$ Abre os olhos à ordem verbal.

Resp. Verbal $=>$ Emite apenas sons.

Resp. Motora $=>$ Faz flexão anormal.

Vítima $02=>$

Resp. Ocular $=>$ Abre os olhos após estímulos dolorosos.

Resp. Verbal $=>$ Emite apenas sons.

Resp. Motora $=>$ Faz flexão anormal.

Vítima $03=>$

Resp. Ocular $=>$ Abre os olhos após estímulos dolorosos

Resp. Verbal $=>$ Confuso.

Resp. Motora $=>$ Faz flexão normal.

Vítima $04=>$

Resposta Ocular $=>$ Abre os olhos após estímulos dolorosos

Resp. Verbal $=>$ Palavras inapropriadas.

Resp. Motora $=>$ Faz flexão normal.
a) Vítima 01, Vítima 02, Vítima 03, Vítima 04.
b) Vítima 04, Vítima 03, Vítima 02, Vítima 01.
c) Vítima 03, Vítima 01, Vítima 04, Vítima 02.
d) Vítima 02, Vítima 01, Vítima 04, Vítima 03.
e) Vítima 04, Vítima 02, Vítima 01, Vítima 03.

14) São os 5 P's da síndrome compartimental:

a) Paralisia, parestesia, paresia, pulso ausente e perda de calor.

b) Paresia, pulso ausente, perda de calor, pressão e dor.

c) Palidez, pulso ausente, prostração, paralisia e pânico.

d) Paralisia, parestesia, pulso ausente, palidez e dor.

e) Perda de calor, paresia, palidez, pirose e pânico.

15) Faz parte da tríade de Beck, EXCETO:

a) Sons cardíacos abafados.

b) Hipotensão.

c) Jugulares túrgidas.

d) Paralisia.

e) N.D.A.

16) Fazem parte das 5 regras da imobilização, exceto:

a) Checar pulso antes e depois.

b) Passar por cima lesão.

c) Imobilizar do jeito que encontrou.

d) Em lesões ósseas, imobilizar a articulação proximal e distal.

e) Em lesões articulares, imobilizar o osso proximal e distal.

17) Qual é a afirmação errada? 
a) Em um trauma fechado, o mecanismo mais provável de causar ruptura da aorta não é por compressão.

b) Ao se encontrar uma vítima de ferimento penetrante, o socorrista deve avaliar os fe-rimentos de entrada e saída.

c) Os padrões de lesão mais provavelmente encontrados na fase primária de uma explo-são são: ruptura do intestino delgado e pneumotórax hipertensivo.

d) Perfurações dos intestinos podem ocorrer tanto em trauma contuso quanto em trauma penetrante.

e) O papel dos air-bags é diminuir a taxa de desaceleração do ocupante.

18) Quais dos mecanismos abaixo indicam as causas mais frequentes de TRM em crian-ças e adultos, respectivamente?

a) Lesões esportivas / lesões penetrantes.

b) Colisões de veículos / atropelamento.

c) Queda de altura / colisões de veículos.

d) Atropelamento / lesões esportivas.

e) Lesão penetrante / queda de altura.

19) Em uma vítima de grande queimadura por calor, o socorrista deve pensar nas se-guintes complicações, exceto:

a) Desidratação.

b) Infecção secundária.

c) Hipotermia.

d) Síndrome compartimental.

e) Hipernatremia.

20) Devemos pensar em hemorragia interna nas seguintes vítimas, exceto:

a) Choque hipovolêmico de causa não explicada.

b) Mecanismo de trauma com suspeita de ruptura de vísceras abdominais (baço, fígado).

c) Fratura de pelve confirmada por manobra do livro aberto.

d) Vítimas de choque hemorrágico que respondem de forma insatisfatória à reposição volêmica com solução cristaloide.

e) N.D.A.

21) São passos essenciais para o resgate imediato e tratamento de uma vítima de afoga-mento, exceto:

a) Segurança de cena.

b) Suspeitar de lesão de coluna cervical em vítimas inconscientes afogadas em local raso.

c) Iniciar as manobras de ressuscitação o quanto antes, ainda dentro da água.

d) Reverter a hipóxia e a acidose.

e) Remover todas as roupas molhadas da vítima.
22) Devemos suspeitar de lesão neurológica com aumento da pressão intracraniana (PIC) quando houver, principalmente:

a) Hipertensão arterial sistólica, bradicardia e bradipneia.

b) Equimose periorbital, saída de líquor pela cavidade nasal e cefaleia.

c) Hipertensão arterial sistólica, cefaleia e equimose periorbital.

d) Cefaleia intensa, hemiparesia facial e hipertensão arterial sistólica.

e) Pupilas assimétricas, cefaleia e hemiparesia facial.

23) Sobre lesões por arma de fogo, veja as afirmativas abaixo, e marque a alternativa adequada:

I- Quanto maior a distância de disparo, maior será o orifício de entrada.

II- Devemos nos atentar sempre a quantidade de energia cinética do projetil, pois é esta energia que se transformará em lesão.

III- No orifício de saída não pode haver a típica zona de queimadura.

IV- Quanto maior o calibre da munição, maior será a energia do projetil disparado.

a) Todas são verdadeiras.

b) Apenas duas são verdadeiras.

c) Apenas uma é falsa.

d) Três são falsas.

e) Todas são falsas. 